\title{
A Call for Metacognitive Intervention: Improvements Due to Curricular Programming in Leadership
}

\author{
Melissa S. Terlecki, PhD. \\ Cabrini University \\ Anne McMahon \\ Cabrini University
}

\begin{abstract}
Metacognition is linked to academic achievement and personal development, especially as it relates to leadership education. The current study investigated the impact of a course in metacognition. Two hundred and fifty one undergraduates were surveyed for metacognitive ability using the Metacognitive Awareness Inventory (MAI) and Metacognitive Rubric (MR) before and after participating in a course either involving metacognitive training or alternative coursework. While minimal demographic differences were found, results showed significant improvement among students who trained in the metacognition class. Curricular development in the area of metacognition is recommended as it relates to leadership education.
\end{abstract}

\section{Introduction}

Understanding how one thinks and processes information is critical to academic success, personal development, and career and professional advancement. Metacognition, or "one's knowledge concerning one's own cognitive processes or anything related to them" (Flavell, 1976, p. 232), has been simplified to "cognition about cognition," or, in other words, thinking about thinking (p. 104). In the field of leadership education, self-awareness or metacognition is tantamount. It has been liked to emotional intelligence (Steiner, 2017) and authentic (Bratton, Dodd, \& Brown, 2011; Kinsler, 2014) and transformational leadership (Eriksen, 2009; Walumbwa \& Wernsing, 2013) models. Likewise, the Social Change Model of Leadership (Astin \& Astin, 1996) identifies "consciousness of self" as a major factor in leadership development, which involves awareness of the beliefs, values, attitudes and emotions that motivate one to take action, which also are key in understanding those intentions of others. Selfawareness involves monitoring and controlling one's own behavior, while incorporating feedback from others (Steiner, 2017).

Generally, metacognition is broken down into two parts: knowledge of cognition and regulation of cognition (Brown, 1987; Buchard \& Swerdzewski, 2009; Lai, 2011; Mytkowicz, Goss, \& Steinberg 2014; Zulkiply, Kabit, \& Ghani, 2009; for example). Knowledge of cognition consists of the general understanding of cognition, including strategies for improving cognition, and what impacts one's own cognition (Wagener, 2013). Cognition can be broken down into declarative knowledge (knowing strategies and personal abilities), procedural knowledge (knowing how to carry out strategies), and conditional knowledge (knowing when and why to use strategies) (Buchard \& Swedzewski, 2009; Schraw \& Dennison, 1994). Regulation of cognition can be defined as the management and control of one's cognition in order to complete 
a task (Zulkiply et al., 2009). Schraw and Dennison (1994) claim that regulation includes skills of planning, information management, comprehension monitoring, debugging strategies, and evaluation.

While constructs are often confused with one another, metacognition is distinct from critical thinking or cognition alone. Metacognitive strategies incorporate higher-level thinking, but the critical distinction is that metacognition involves the awareness of one's thinking. Kolencik and Hilwig (2011) claim that acknowledging and processing our own thinking takes cognition to another, more challenging level. They argue that strength in metacognitive skill and understanding improves time management, organizational skills, independence, and confidence, which contribute to success not just in academics, but life in general. Likewise, Tomlinson and McTighe (2006) agree, "the most effective learners are metacognitive" (p. 79), due to mindfulness, goal setting, self-assessment, performance adjustment, and strategy-selection. In general, those with metacognitive skill and understanding have greater awareness of the efforts they as individuals need to commit to strengthen personal learning and growth (Kolencik \& Hillwig, 2011).

Leadership education specifically targets growth in these areas (Aas, 2017; Jensen, 2011). Some argue that self-aware leaders prime themselves for more career advancement opportunities through greater skill in critical and systems thinking, savvy perspective of politics, and greater drive for magis (Gallagher, 2012). Metacognition can empower individuals to realize their own unique potentials, as well as the capacity of their organizations and those they work with (Caldwell \& Hayes, 2016). Anticipating the perspectives of others can allow leaders gain insight regarding leader influence (Taylor, 2010). Aas (2017) finds that educational programs that include opportunities for metacognitive reflections supports leaders to become learners with the capacity to make changes in their leadership practices, as well as in their school.

Empirical research backs up these claims. Studies show students who score high on metacognitive measures generally have been found to academically outperform those who do not (Rezvan, Ahmadi, \& Abedi, 2006; Zulkiply et al., 2006). Zulkiply et al. (2009) studied this relationship at a private secondary school in Malaysia including 73 students (aged 14 to 19 years). Metacognitive knowledge and regulation was measured using the Metacognitive Awareness Inventory (MAI), and students' academic performance was measured using average examination scores. A positive correlation between MAI performance and academic achievement was found. Students who scored higher in metacognition performed better, academically.

Using more deliberate methods, researchers have also evaluated the effects of training in metacognition on academic performance. Rezvan et al., (2006) conducted a study that involved 60 female university students who were all academically at-risk. Half of the participants were randomly selected for the experimental group that took part in 6 metacognitive training sessions (lasting from 1.5-2.5 hours each). Throughout the sessions, the participants learned about the definition of metacognition and its components, problem solving, and explored personal metacognitive beliefs (journaling) through individual and group work. First semester academic records were used as a pretest measure while second semester scores were used as the posttest 
measure. Results showed that metacognitive training yielded improvement in academic achievement between first and second semester scores.

Other research aims at understanding the relationship between metacognitive training and the improvement of specific, related skills, such as problem solving, goal setting, and predictions of performance. Sandi-Urena, Cooper, and Stevens (2011) assessed the effects of an intervention program that sought to improve metacognitive skill and problem solving abilities in students from a General Chemistry Laboratory course. The study included over 1,000 students. The experimental group participated in collaborative and individual work on assignments involving general problem solving (i.e., planning, monitoring, and evaluating). There were three phases of the intervention. Phase one, the collaboration component, took about 45 minutes. Phase two, the individual take home assignments, took about 20-30 minutes. Finally, feedback was offered at an individual level in phase three for about ten minutes. Both the treatment and control groups took the Metacognitive Activities Inventory (MCAI) (Cooper \& Sandi-Urena, 2009) and the Interactive Multimedia Exercises Software (IMMEX) (Cooper, Cox, Nammouz, Case, \& Stevens, 2008) at pre- and posttest. The MCAI was used to assess metacognitive skill while solving chemistry problems and the IMMEX, a web-based tool, was used for assessing performance and problem solving in chemistry. Those who participated in the intervention (experimental group) became better able to solve difficult chemistry problems and became more critical of themselves and their use of metacognitive and problem solving skills.

Similarly, Cornoldi, Carretti, Drusi, and Tencati (2015) created a training program focused on metacognition and working memory, and the relationship to problem solving abilities. The study involved 135 students (aged $8-10$ years) from a school in Northern Italy. Half of the students participated in 8 training sessions between October to December and the other half participated in the same 8 training sessions between January and March. Each training session was about an hour long, and there was one session every week for 8 weeks. The training involved completing working memory tasks, metacognitive activities, and discussions on problem solving (and how working memory and metacognitive exercises relate to problem solving). Assessments included the Questionnaire on Metacognition in Mathematics (adapted from Cornoldi, Caponi, Focchiatti, Lucangeli, Todeschini, \& Falco G., 1995), the Working Memory Updating Task (an adaptation of the task proposed by Palladino, Cornoldi, De Beni, and Pazzaglia, 2001), and the Arithmetical Problem-Solving Tasks AC-MT (Cornoldi, Lucangeli \& Bellina, 2012). A significant improvement was found on the metacognitive questionnaire, the working memory task, and the arithmetical task. Students who were lowest achieving academically benefitted the most from the program. Even 3 months later, improvements remained. Thus, interventions may have long-lasting effects.

Metacognition has also been linked to perceptions of self-efficacy. Miller and Geraci (2011) argue that improving metacognitive monitoring ability is linked to more accurate predictions about self-performance. The first of two experiments involved 130 students from a Cognitive Psychology course. During this experiment, the incentive of 2 percentage points of extra credit was offered to students if they accurately predicted their exam scores. After each exam was returned, the instructor offered minimal feedback by putting the average scores and average predictions online and advising students to evaluate their own predictions. The second experiment involved 81 students who were also from a Cognitive Psychology course. The 
protocol was the same except individual grades, predictions, and extra credit were all posted online. The instructor also described the scores more in depth and further advocated using metacognitive calibration to better their scores. Predictions of exam performance did not significantly increase after minimal feedback, but low performing students became better predictors after stronger feedback (second condition) was provided (did not significantly increase in academic performance; their predictions became more accurate).

Although empirical evidence points to the relationship between metacognitive training and academic performance related to specific, varying skills, research should also focus on the effectiveness of metacognitive intervention and training for its own sake. A meta-analysis looking at metacognitive training in younger students included 48 studies (Dignath, Buettner, \& Langfeldt, 2008). All studies were conducted as part of a course in school, had a control group, were longitudinal, and included at least 10 participants. The programs had to involve direct strategy instruction aimed at improving self-regulation. Three types of strategies could have been incorporated in the training: cognitive strategies, metacognitive strategies, or theoretical background on social-cognitive, metacognitive, or motivational elements. In the samples of first through sixth grade school students, direct strategy training on self-regulation increased cognitive and metacognitive strategy usage, academic achievement, and motivation.

Cross and Paris (1988) conducted a similar study involving metacognitive training for students in third and fifth grade. Of the 171 students in the 8 classes from 4 separate schools that incorporated the training program, half were randomly assigned to the experimental group that took part in the Informed Strategies for Learning (ISL) training program (Cross and Paris, 1988). The program was four months long and focused on improving cognitive awareness and the use of reading strategies. The sessions were interactive and students learned declarative, procedural, and conditional information regarding reading strategies. At both pre- and posttest, the Comprehension subtest of the Gates-MacGinitie Reading Test (MacGinitie, 1978) was used to measure reading comprehension; a cloze task and an error detection task (Cross \& Paris, 1988) were used to measure strategic reading; and a structured interview (Paris \& Jacobs, 1984) including a strategy ratings task (Paris \& Myers, 1981) were used to evaluate reading awareness. The experimental groups from both grade levels made significant improvements in metacognition and the use of reading strategies from pretest to posttest.

Metacognitive training has also been effective with college-aged populations. Buchard and Swerdzewskil (2009) studied the effects of a 16-week strategic learning course on metacognitive strategy usage in 78 students from a mid-Atlantic university. The course covered learning theories such as goal orientation and setting, metacognition, change theory, memory, and multiple intelligences. Students were taught how to relate these theories to their own learning by writing reflections, participating in group discussions, and carrying out class projects. Finally, students were taught how to apply metacognitive strategies and theory through practice such as creating mnemonic devices or using reasoning to overcome a difficult problem. The MAI was taken before the training began and again during the $13^{\text {th }}$ week. Compared to control students $(N=1,463)$ not taking the course, significant increases in the Awareness and Regulation subscales of the MAI were found from pretest to posttest. Of note, $44 \%$ of the sample had recorded cognitive disabilities. However, no interaction between cognitive disability and 
MAI scores were found, meaning students with or without disabilities benefitted similarly from the course.

Likewise, Mytkowicz et al., (2014) focused in on metacognitive gains in college-aged students with learning disabilities (LD) or attention deficit (hyperactivity) disorder (ADHD). The MAI measured metacognitive ability of 48 students before and after a first-year, two-semester strategic learning course. Some of the course objectives included teaching personal learning styles and strategies to improve learning. The course also taught strategy selection and awareness of personal strategy usage. GPAs from the fall to spring semester were compared. Significant improvements in metacognitive awareness from pretest to posttest were found, and MAI scores were significantly, positively correlated to GPAs. These studies support the claim that metacognition can be improved among all students, regardless of initial academic achievement or learning disability (Kolencik \& Hillwig, 2011). Buchard and Swerdzewski (2009) agree that not only can metacognitive strategies be taught, but also that explicit training is necessary to influence the metacognition of all learners.

While plenty of research and literature supports the importance of learning metacognitive strategies, few studies empirically measure the effectiveness of a comprehensive course in metacognition. Such empirical assessment is critical in developing more effective leadership curricula, as it relates to self-awareness components (Ashley \& Reiter-Palmon, 2012). The current study aims to measure the impact of teaching metacognition as a college-level course in leadership programming. Initial and follow up measures of metacognitive awareness, regulation, and skill were compared between students enrolled in Cognition, Metacognition, and Introduction to Psychology courses. It was expected explicit metacognitive training as part of a Metacognition course would produce the greatest increase in metacognitive awareness, regulation, and skill from pretest to posttest.

\section{Methods}

Participants. The sample included 251 predominately female $(81 \%)$ undergraduate students from a wide variety of majors (although a majority were Psychology majors; $55 \%$ and Leadership minors $22 \%$ ) from a small, private liberal arts school in the northeast United States. With an undergraduate population of $<1,500$, students are $62 \%$ Caucasian $(22 \%$ Black or African American, 11\% Hispanic, and 5\% other) and 62\% female (38\% male). Of the participants, 75 were freshman (29.8\%), 59 were sophomores (23.4\%), 34 were juniors (13.5\%), and 80 were seniors $(32.1 \%)$. Participants were all enrolled in at least one of three psychology courses: Laboratory Experiences in Cognition $(N=33)$, Metacognition $(N=67)$, or Introduction to Psychology $(N=151)$. Prior to taking the assessments, 38 students had previously taken Metacognition, and 30 had taken Laboratory Experiences in Cognition. Introductory and Metacognition students were from varied majors and levels, while upperclass Psychology majors took Cognition.

Materials. Basic demographics were collected from participants on the first page of the assessment. These items included questions regarding gender and grade level (freshman through senior status), but also whether or not participants had taken any related academic coursework. Participants were surveyed as to whether they had previously taken Metacognition or Laboratory 
Experiences in Cognition, given that these courses may overlap in some cognitive content. However, there are significant differences between these courses in pedagogy. While the Laboratory course in Cognition covers content in learning, memory, and problem solving (among other areas) through lecture and laboratory (computerized experiments in research methods), the Metacognition course, similar to Burchard and Swerdzewski (2009), applies cognitive and metacognitive content through activities and experiences inside and outside of the classroom. Students are involved in numerous reflective exercises and assessments that encourage self-awareness of cognitive (learning, memory, problem solving, reasoning), emotional, social, personality, motivational and achievement dimensions related to leadership development. Students in the Metacognition course are empowered to understand their own thinking patterns and processes and reflect on applications and implications in life and future success as leaders. This course is much more immersive and personalized for students in understanding their own cognition, and can be considered direct training in such. Although the laboratory course is also experiential in nature, metacognitive strategies are not employed. Of note, Introduction to Psychology also covers many areas of learning, memory, and problem solving (among others), but much less in depth and is purely lecture format (thus previous experience in this class was not assessed).

The Metacognitive Awareness Inventory (MAI). The Metacognitive Awareness Inventory (MAI) (Schraw \& Dennison, 1994) was used in this study to measure metacognitive awareness and regulation. The survey originally consisted of 52 true/false questions but was revised to use the same five-point Likert-type rating scale (as the MR below), ranging from "I never do this" to "I do this always." Some of the questions on the MAI include, "I consider several alternatives to a problem before I answer," "I understand my intellectual strengths and weaknesses," "I have control over how well I learn," and "I change strategies when I fail to understand." This assessment is widely used and reliability and validity measures are available. Schraw and Dennison (1994) found an alpha coefficient of .91 on each factor of the MAI and .95 for the entire MAI, which indicates reliability. Pintrich (2000) agrees the MAI has external validity given MAI scores and students' academic achievement are highly correlated.

Thinking as a Learner: Metacognitive Rubric (MR). The Metacognitive Rubric (MR) was also used in this study to measure metacognitive skill (Kolencik \& Hillwig, 2011). The survey consisted of 13 Likert-type questions revised to fit a fivepoint scale (in order to have a center point of measure), which ranged from "I never do this" to "I always do this." Some of the questions on the MR include, "I periodically monitor the thinking strategies I use," "I use a system for solving problems" and "I develop my ability to apply my prior knowledge to new problems and situations." This measure was proposed by the authors to use as a metacognitive exercise.

The MAI and MR were combined to form a singular, 65-question survey that was administered as a pre- and posttest assessment. Both were converted to a five-point Likert-type scale for consistency and to combine scores in order to estimate overall metacognition (although both measures were also individually analyzed). True/False dichotomies are especially difficult to use as a measure of growth, and thus Likert-type scales, with mid-points were preferred. 
Procedure. Research was initially approved by the Institutional Review Board. Participants in this study were enrolled in one of three undergraduate courses: Laboratory Experiences in Cognition, Metacognition, and/or Introduction to Psychology (control). These courses were selected for comparison to specifically measure the effect of metacognitive pedagogy compared to metacognitive content alone (in addition to a control). Cognition is offered to upper class Psychology majors once an academic year. Introduction and Metacognition are offered every semester. Metacognition is often part of a freshman learning community in leadership (cohorts of freshmen take linked classes) and also offered as a required course part of a Leadership minor. Multiple sections of Introduction are offered each semester, enrolling students from varying levels and majors. Previous experience in Introduction was not assessed, as overlap in content is minimal.

The combined survey (MAI and MR) was administered at the beginning and end of the semester/s (within the first and last two weeks of academic classes). All measures were untimed, but took participants approximately 10 minutes to complete. A consent form was attached to the front of the assessment and was explained before distribution. Participation was optional and roughly $95 \%$ of students enrolled in the aforementioned classes participated for extra credit points (in their respective courses). Pre- and posttest measures were unmatched, and all survey responses were confidential. When surveys were completed, students turned them in anonymously at the front of the room, either facing down or in an envelope. Data from the surveys was entered and analyzed using IBM SPSS Statistics, Version 23.

\section{Results}

Preliminary descriptive analyses showed that when pre- and posttest data were combined, the average score on the MAI was $M=3.90(0.47)$ and the MR was $M=3.73(0.55)$, (see Table 1$)$. At pretest, the average on the MAI was $M=3.82(0.47)$, and the average score on the MR was $M=3.66$ (0.52). At posttest, the average score on the MAI score was $M=3.97(0.46)$ and the MR was $M=3.80(0.58)$ (see Table 2).

Table 1

Descriptive Statistics for Overall MAI and MR Scores

\begin{tabular}{ccccccc} 
& $\mathrm{N}$ & $M$ & $\begin{array}{c}\text { Std. } \\
\text { Deviation }\end{array}$ & Minimum & Maximum & $\begin{array}{c}95 \% \\
\text { Confidence } \\
\text { Interval }\end{array}$ \\
\hline Overall MAI & 251 & 3.90 & 0.47 & 2.40 & 5.00 & {$[3.84,3.96]$} \\
\hline Overall MR & 251 & 3.73 & 0.55 & 2.23 & 5.00 & {$[3.66,3.80]$} \\
\hline
\end{tabular}


Table 2

Descriptive Statistics for Overall MAI and MR Scores at Pre-and Posttest

\begin{tabular}{cccccccc} 
& Time & $\mathrm{N}$ & $M$ & $\begin{array}{c}\text { Std. } \\
\text { Deviation }\end{array}$ & Minimum & Maximum & $\begin{array}{c}95 \% \\
\text { Confidence } \\
\text { Interval }\end{array}$ \\
\hline $\begin{array}{c}\text { Overall } \\
\text { MAI }\end{array}$ & Pre & 126 & 3.82 & 0.47 & 2.87 & 4.83 & {$[3.74,3.91]$} \\
\hline Post & 125 & 3.97 & 0.46 & 2.40 & 5.00 & {$[3.89,4.05]$} \\
$\begin{array}{c}\text { Overall } \\
\text { MR }\end{array}$ & Pre & 126 & 3.66 & 0.52 & 2.46 & 4.85 & {$[3.57,3.75]$} \\
& Post & 125 & 3.80 & 0.58 & 2.23 & 5.00 & {$[3.70,3.90]$}
\end{tabular}

A Pearson Correlation showed a significant, positive relationship between MAI and MR scores across groups, $r=.71, p<.001, N=251$. Within all three classes, significant correlations were found between MAI and MR scores: Cognition ( $r=.77, p<.001, N=33)$, Metacognition $(r=.75, p<.001, N=67)$ and Introduction $(r=.68, p<.001, N=151)$. Across groups, at pretest, a significant, positive correlation was found between MAI and MR scores, $r=.73, p<.001, N=126$. Likewise, at posttest, MAI and MR scores were also correlated, $r=.69, p<.001, N=125$, showing that improvements on one metacognitive assessment were related to improvements on the other, over time (see Figure 1).

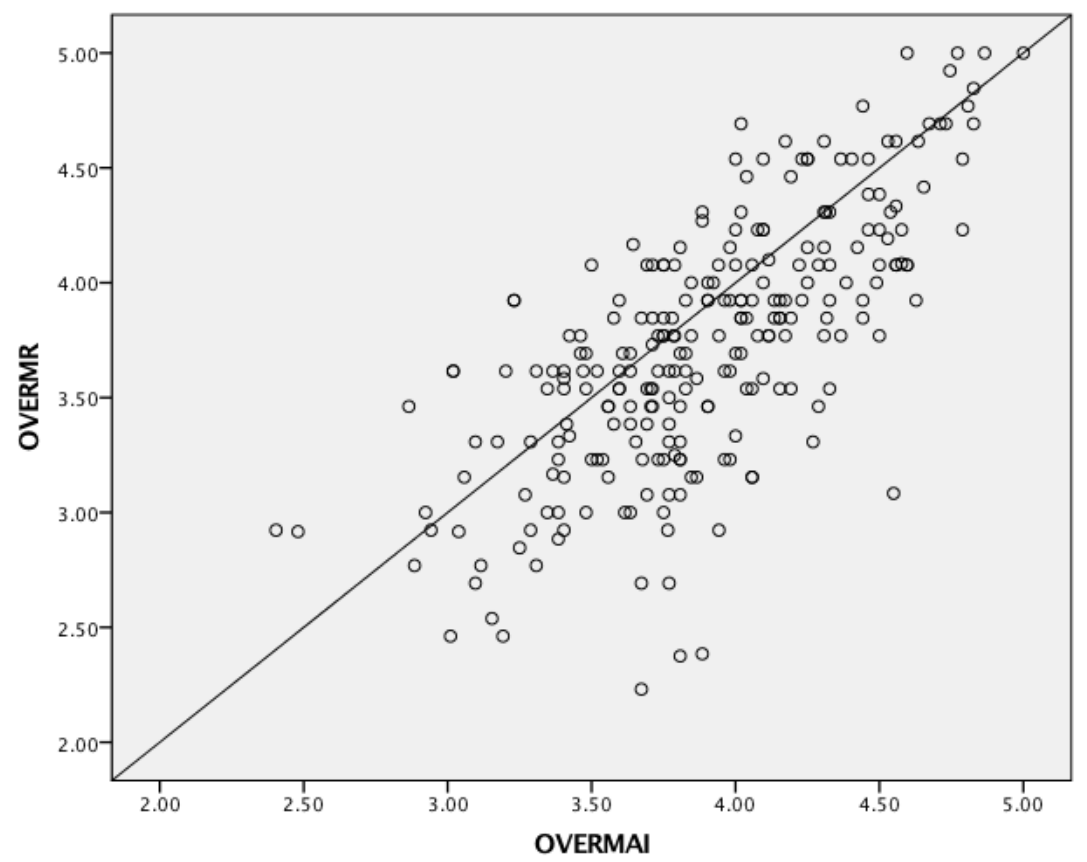

Figure 1. Scatterplot of Overall MAI and MR Scores 
A $3 \times 2$ multivariate analysis of variance (MANOVA) was conducted to reveal the effect of the three classes (Cognition, Metacognition, and Introduction to Psychology) on the two dependent variables: overall MAI and MR scores. A significant main effect was found between classes for the overall MAI score, $F(2,248)=3.39, p=.04, \eta_{\mathrm{p}}{ }^{2}=.03$. Power to detect the effect was .64. No main effect was found between classes on overall MR score.

Pairwise comparisons were included in post-hoc analyses to determine which classes differed in MAI score. A significant difference was found between Cognition and Metacognition students $(p=.02, d=0.24)$ and between Cognition and Introduction students $(p=.02, d=0.22)$, but not between Metacognition and Introduction students $(p=.72, d=0.02)$. Overall (across both pretest and posttest), Cognition students reported greater, overall metacognition than Metacognition and Introduction students (see Table 3). This effect disappears when controlling for gender and grade level (freshman through senior status), and time, $F(2,248)=.44, p=.64, \eta_{\mathrm{p}}{ }^{2}$ $=.00, \mathrm{P}=.12$.

Table 3

Means and Standard Deviations for MAI and MR Scores within Groups

MAI Score $\quad$ MR Score

\begin{tabular}{cccccc} 
Class & $\mathrm{N}$ & $M$ & SD & $M$ & SD \\
\hline Cognition & 33 & 4.09 & 0.47 & 3.87 & 0.66 \\
\hline Metacognition & 67 & 3.85 & 0.49 & 3.70 & 0.58 \\
\hline Introduction & 151 & 3.88 & 0.45 & 3.71 & 0.55
\end{tabular}

However, when separating by time (pre- versus posttest), a 2 × 3 multivariate analysis of variance (MANOVA) revealed no change between pre and posttest scores for Introduction or Cognition students. A significant main effect between pre and posttest scores for Metacognition students was found, $F(1,65)=6.24, p<.001, \eta_{\mathrm{p}}{ }^{2}=.16, \mathrm{P}=.88$, such that students significantly increased overall metacognition by posttest on both the MAI, $F(1,32)=12.62, p<.001, \eta_{\mathrm{p}}{ }^{2}=.00$, $\mathrm{P}=.94$, and the $\mathrm{MR}, F(1,31)=7.21, p=.01, \eta_{\mathrm{p}}{ }^{2}=.10, \mathrm{P}=.75$ (see Table 4). 


\section{Table 4}

Means and Standard Deviations for MAI and MR Scores at Pre-and Posttest within Groups

\begin{tabular}{|c|c|c|c|c|c|}
\hline Course & Measure & Time & $\mathrm{N}$ & $M$ & $\mathrm{SD}$ \\
\hline \multirow{4}{*}{ Cognition } & MAI & Pre & 17 & 3.96 & 0.44 \\
\hline & \multirow{3}{*}{ MR } & Post & 16 & 4.23 & 0.48 \\
\hline & & Pre & 17 & 3.76 & 0.50 \\
\hline & & Post & 16 & 3.98 & 0.80 \\
\hline \multirow{4}{*}{ Metacognition } & MAI & Pre & 33 & 3.65 & 0.53 \\
\hline & \multirow{3}{*}{ MR } & Post & 34 & 4.05 & 0.37 \\
\hline & & Pre & 33 & 3.51 & 0.59 \\
\hline & & Post & 34 & 3.88 & 0.51 \\
\hline \multirow{4}{*}{ Introduction } & MAI & Pre & 76 & 3.87 & 0.43 \\
\hline & \multirow{3}{*}{ MR } & Post & 75 & 3.88 & 0.47 \\
\hline & & Pre & 76 & 3.70 & 0.48 \\
\hline & & Post & 75 & 3.73 & 0.55 \\
\hline
\end{tabular}

When looking at grade level of participants within Metacognition, $49 \%$ were seniors and $39 \%$ were freshmen (leaving only 8 students as sophomores or juniors). Further comparison was warranted, using a 2 x 2 multivariate analysis of variance (MANOVA), showing main effects for time (pre- versus posttest), $F(2,57)=6.77, p<.001, \eta_{\mathrm{p}}{ }^{2}=.20, \mathrm{P}=.90$, and grade level (freshman versus senior status), $F(2,57)=10.70, p<.001, \eta_{\mathrm{p}}{ }^{2}=.28, \mathrm{P}=.99$. Seniors scored higher than freshmen at both pretest, $t(28)=-3.77, p<.001$ and posttest, $t(28)=-2.60, p=.02$, on the MAI, but only at pretest, $t(27)=-2.57, p=.02$, on the MR (see Table 5). 


\section{Table 5}

Means and Standard Deviations for MAI and MR Scores Pre- and Posttest within Grade Level

\begin{tabular}{|c|c|c|c|c|c|}
\hline & Time & Grade Level & $\mathrm{N}$ & $M$ & SD \\
\hline & & Freshman & 13 & 3.37 & 0.35 \\
\hline & Pre & Senior & 16 & 4.00 & 0.50 \\
\hline & & Total & 29 & 3.70 & 0.53 \\
\hline & & Freshman & 13 & 3.89 & 0.22 \\
\hline \multirow[t]{9}{*}{ MAI } & Post & Senior & 17 & 4.20 & 0.39 \\
\hline & & Total & 30 & 4.07 & 0.36 \\
\hline & & Freshman & 26 & 3.63 & 0.39 \\
\hline & Total & Senior & 33 & 4.10 & 0.46 \\
\hline & & Total & 59 & 3.89 & 0.48 \\
\hline & & Freshman & 13 & 3.23 & 0.33 \\
\hline & Pre & Senior & 16 & 3.74 & 0.65 \\
\hline & & Total & 29 & 3.51 & 0.58 \\
\hline & & Freshman & 13 & 3.81 & 0.34 \\
\hline \multirow[t]{5}{*}{ MR } & Post & Senior & 17 & 4.02 & 0.59 \\
\hline & & Total & 30 & 3.93 & 0.50 \\
\hline & & Freshman & 26 & 3.52 & 0.44 \\
\hline & Total & Senior & 33 & 3.89 & 0.63 \\
\hline & & Total & 59 & 3.73 & 0.58 \\
\hline
\end{tabular}

Because similar content may be covered across the various courses, previous participation in Metacognition and Cognition was assessed. A one-way multivariate analysis of variance (MANOVA) was conducted to determine the effect of having those classes on MR and MAI performance at pretest. Having Cognition had an effect on MR performance, $F(1$, $194)=7.26, p=.01, \eta_{\mathrm{p}}{ }^{2}=.04, \mathrm{P}=.77$ ) only. No main effects were found for having Metacognition prior.

\section{Discussion}

Can metacognition be taught? Can students improve their levels of self-awareness after a semester-long intervention in metacognitive training as part of leadership curricula? In line with previous research, the answer is yes. Although most research has been conducted with younger or at-risk samples on specialized domains of knowledge, even short-term interventions have yielded improvements on metacognitive measures. The current study compliments this literature by testing college-aged students not pre-identified as having a disability or being at-risk, but by 
assessing global metacognitive improvements across regulation and awareness through the MAI (Metacognitive Awareness Inventory), alongside an additional survey of skill (MR;

Metacognitive Rubric), often used to measure these constructs. The aforementioned intervention was curricular and immersive; embedded into leadership content and pedagogy/instruction. When compared to other courses with similar or dissimilar content, yet lacking the metacognitive engagement, this intervention yielded significant results. This is significant given freshmen and seniors enrolled in leadership programming both benefitted (regardless of developmental maturation).

Although performance on both MAI and MR measures correlated, significant improvements were mostly relegated to the MAI. This makes sense given the MAI is a more robust, lengthy measure. Overall, Cognition students began with greater metacognitive scores compared to other students, while Metacognition students yielded the lowest performance, though demographics may have played a role here. However, Metacognition students showed the greatest growth in metacognition from pre- to posttest on the MAI and MR (and therefore had the greatest room for improvement). Nearly all Cognition students were upperclassmen (compared to Metacognition students who were roughly split between freshmen and senior status) and had taken a laboratory course which covers learning cognitive content (Laboratory Experiences in Cognition) and thus, exposure may have been cumulative. This effect is not surprising and yet encouraging that significant growth in metacognition can be witnessed, despite initial ability level. Regardless of group or demographic differences, initial and final performance across all participants was by no means hitting ceiling, suggesting much more room for metacognitive improvement.

Collectively, these studies provide evidence that metacognition can be improved among all students, regardless of ability or status (Kolencik \& Hillwig, 2011). Metacognitive training is important - some may argue crucial - for healthy self-awareness and academic success and an integral component in leadership education (regardless of theoretical perspective underlying programming, as self-awareness is a facet of most). The current study shows that not just learning about metacognitive or cognitive concepts makes the difference - pedagogy applying metacognitive strategies and interventions is what counts. It is argued that metacognitive interventions should take place often and early on in students' academic careers, as previous research also supports. Gaining skill in metacognitive awareness and regulation would have a significant impact on learning in any course or life skill, but is especially effective in leadership training. As Caldwell and Hayes (2016) argue, "ethical leaders owe it to others and themselves to be more effective through a greater understanding of self-efficacy and self-awareness". Metacognitive training encourages more self-concordant goals in authentic leadership (Kinsler, 2014). And, as Ashley \& Reiter-Palmon (2012), argue for a better measurement of selfawareness, the MAI may provide fruitful evidence for metacognitive growth in leadership development. An increase in empirical studies on the effect of metacognitive pedagogy and assessment instruments is suggested to more effectively implement self-awareness into leadership curricula. As Steiner (2017) aptly puts, "lifelong learning and development depends on accurate and meaningful knowledge about us as individuals". 


\section{References}

Aas, M. (2017). Leaders as learners: Developing new leadership practices. Professional Development in Education, 43(3), 439-453.

Ashley, G. \& Reiter-Palmon, R. (2012). Self-awareness and the evolution of leaders: The need for a better measure of self-awareness. Journal of Behavioral and Applied Management, 14(1), 2-17.

Astin, H., \& A. Astin (1996). A social change model of leadership development guidebook: Version III. The National Clearinghouse of Leadership Programs.

Bratton, V., Dodd, N., \& Brown, F. (2011). Authentic leadership: Practical reflexivity, selfawareness, and self-authorship. Leadership \& Organization Development Journal, 32(2), $127-149$.

Brown, A. L. (1987). Metacognition, executive control, self-regulation, and other more mysterious mechanisms. In F. E. Weinert \& R. H. Kluwe (Eds.), Metacognition, motivation, and understanding (pp. 65-116). Hillsdale, New Jersey: Lawrence Erlbaum Associates.

Burchard, M. S., \& Swerdzewski, P. (2009). Learning effectiveness of a strategic learning course. Journal of College Reading and Learning, 40(1), 14-34.

Caldwell, C. \& Hayes, L. (2016). Self-efficacy and self-awareness: Moral insights to increased leader effectiveness. Journal of Management Development, 35(9), 1163-1173.

Cooper, M. M., Cox, C. T., Nammouz, M., Case, E., \& Stevens, R. H. (2008). An assessment of the effect of collaborative groups on students' problem solving strategies and abilities. Journal of Chemical Education, 85(6), 866-872.

Cooper, M. M., \& Sandi-Urena, S. (2009). Design and validation of an instrument to assess metacognitive skillfulness in chemistry problem solving. Journal of Chemical Education, $86(2), 240-245$.

Cornoldi, C., Caponi, B., Focchiatti, R., Lucangeli, D., Todeschini, M., \& Falco, G. (1995). Matematica e metacognizione [Mathematics and metacognition]. Trento, Italy: Centro Studi Erickson.

Cornoldi, C., Carretti, B., Drusi, S., \& Tencati, C. (2015). Improving problem solving in primary school students: The effect of a training programme focusing on metacognition and working memory. British Journal of Educational Psychology, 85(3), 424-439. doi:10.1111/bjep.12083 
Cornoldi, C., Lucangeli, D., \& Bellina, M. (2012). Test AC-MT 6-11-Test di valutazione delle abilita_di calcolo e soluzione di problemi [AC-MT test-Assessment of arithmetic and problem solving skills]. Trento, Italy: Centro Studi Erickson.

Cross, D. R., \& Paris, S. G. (1988). Developmental and instructional analyses of children's metacognition and reading comprehension. Journal of Educational Psychology, 80(2), 131-142. doi:10.1037/0022-0663.80.2.131

Dignath, C., Buettner, G., \& Langfeldt, H. P. (2008). How can primary school students learn self-regulated learning strategies most effectively? A meta-analysis on self-regulation training programmes. Educational Research Review, 3(2), 101-129.

Eriksen, M. (2009). Are we on the same page? Effects of self-awareness of empowering and transformational leadership. Journal of Management Education, 33(6), 747-771.

Flavell, H. (1976). Metacognitive aspects of problem solving. In L. B. Resnick (Ed.), The nature of intelligence (p. 231-235). Hillsdale, N: Erlbaum.

Flavell, H. (1985). Cognitive development (2nd ed.). Englewood Cliffs, NJ: Prentice Hall.

Gallagher, D. (2012). The self-aware leader: A proven model for reinventing yourself. Peoria, IL: Versa Press.

Jensen, M. (2011). Nurturing self-knowledge: The impact of a leadership development program. OD Practitioner, 43(3), 30-35.

Kinsler, L. (2014). Born to be me... who am I again? The development of authentic leadership using evidence-based leadership coaching and mindfulness. International Coaching Psychology Review, 9(1), 92-105.

Kolencik, P. L., \& Hillwig, S. A. (2011). Encouraging metacognition: Supporting learners through metacognitive teaching strategies. Educational Psychology: Critical Pedagogical Perspectives. Volume 12. Peter Lang New York. 29 Broadway 18th Floor, New York, NY 10006.

Lai, E. R. (2011). Metacognition: A literature review. Always learning: Pearson research report.

MacGinitie, W. G. (1978). Gates-MacGinitie Reading Tests. Boston: Houghton-Mifflin.

Miller, T. M., \& Geraci, L. (2011). Training metacognition in the classroom: The influence of incentives and feedback on exam predictions. Metacognition and Learning, 6(3), 303314. doi:10.1007/s11409-011-9083-7

Mytkowicz, P., Goss, D., \& Steinberg, B. (2014). Assessing metacognition as a learning outcome in a postsecondary strategic learning course. Journal of Postsecondary Education \& Disability, 27(1), 51-62. 
Palladino, P., Cornoldi, C., De Beni, R., \& Pazzaglia, F. (2001). Working memory and updating processes in reading comprehension. Memory and Cognition, 29, 344-354.

Paris, S. G., \& Jacobs, J. E. (1984). The benefits of informed instruction for children's reading awareness and comprehension skills. Child Development, 55, 2083-2093.

Paris, S. G., \& Myers, M. (1981). Comprehension monitoring, memory, and study strategies of good and poor readers. Journal of Reading Behavior, 13, 5-22.

Pintrich, P. (2000). Issues in self-regulation theory and research. Journal of Mind and Behavior, $21,213-220$.

Rezvan, S., Ahmadi, S. A., \& Abedi, M. R. (2006). The effects of metacognitive training on the academic achievement and happiness of Esfahan University conditional students. Counselling Psychology Quarterly, 19(4), 415-428. doi:10.1080/09515070601106471

Sandi-Urena, S., Cooper, M. M., \& Stevens, R. H. (2011). Enhancement of metacognition use and awareness by means of a collaborative intervention. International Journal of Science Education, 33(3), 323-340. doi:10.1080/09500690903452922

Schraw, G., \& Dennison, R. S. (1994). Assessing metacognitive awareness. Contemporary Educational Psychology, 19(4), 460-475.

Steiner, P. (2017). The impact of self-awareness process on learning and leading. The New England Journal of Higher Education. Retrieved from http://www.nebhe.org/thejournal/the-impact-of-the-self-awareness-process-on-learningand-leading/

Taylor, S. (2010). Redefining leader self-awareness by integrating the second component of selfawareness. Journal of Leadership Studies, 3(4), 57-68.

Tomlinson, C. A., \& McTighe, J. (2006). Integrating Differentiated Instruction \& Understanding by Design: Connecting Content and Kids. Alexandria, VA: Assoc. for Supervision and Curriculum Development.

Wagener, B. (2013). Autogenic training, metacognition and higher education. Educational Psychology, 33(7), 849-861. doi:10.1080/01443410.2013.785051

Walumbwa, F. \& Wernsing, T. (2013). From transactional and transformational leadership to authentic leadership. In: Rumsey, M. (Ed.), The Oxford handbook of leadership (392400). Oxford: London. Oxford University Press.

Zulkiply, N., Kabit, M. R., \& Ghani, K. A. (2009). Metacognition: What Roles Does It Play in Students' Academic Performance? International Journal of Learning, 15(11), 97-105. 


\section{Author Biographies}

Melissa Terlecki, PhD., is associate professor and chair of psychology at Cabrini University. Melissa's academic and research interests include metacognition (as part of psychology and leadership curricula), spatial ability and gender differences, and media psychology. Melissa holds several leadership positions at the university and enjoys teaching and administrative work. Mst723@cabrini.edu.

Anne McMahon is an honors, undergraduate psychology major at Cabrini University. Anne has presented her research at several symposia and has served as intern and research assistant in the psychology department. She is seen as a leader among her peers and plans to attend graduate school for her doctorate. Amm563@ cabrini.edu. 